International

Medical Society

http://imedicalsociety.org

\title{
Depression Post-Stroke: Clinical Characteristics Associated
}

organal

\begin{abstract}
Adman Câmara Soares Lima ${ }^{1}$, Alana Santos Monte ${ }^{1}$, Escolástica Rejane Ferreira Moura1, Karízia Vilanova Andrade', Márcio Flávio Moura Araújo², Ana Kelve de Castro Damasceno1, Ana Karina Bezerra Pinheiro', Régia Christina Moura Barbosa Castro', Lorena Barbosa Ximenes ${ }^{1}$, Paulo César de Almeida ${ }^{1}$, Priscila de Souza Aquino ${ }^{1}$
\end{abstract}

\section{Abstract}

Depression is an important variable related to the worsening of quality of life in post-stroke patients. This study aimed to identify the prevalence of depression in patients after stroke. It is a cross-sectional study conducted between February and April 2013, 51 patients admitted to specialized stroke unit in a hospital in Fortaleza, Ceará, Brazil. Hamilton Depression Rating Scale was applied to investigate depression. Regarding the modifiable risk factors, physical inactivity was the most significant factor for depression. As regards the neurological deficits, subjects with speech disorders had 2.2 times more likely to get depressive symptoms. The inability to walk did not affect the acquisition of these symptoms. On the comorbidities, non diabetics and heart disease ones had a 30\% chance to further develop depression and hypertension does not influence in this. Thus, the study showed that among patients in the sample, younger women, unemployed, who had companion and had higher levels of education presented a greater chance of depression. We see, on this, the need to expand research in this context with longitudinal studies so these and other factors can be controlled through time.

\section{Introduction}

The World Health Organization (WHO) showed that about 38 million people die for chronic non-communicable diseases (NCDs) each year, $85 \%$ of these deaths are in developing countries, representing a worldwide public health problem [1]. Health In Brazil, the high prevalence of these diseases has been taking place since the 60s, standing out
1 Federal University of Ceará, Fortaleza, CE, Brazil.

2 University of the International Integration of African-Brazilian Portuguese language.

Contact information:

Adman Câmara Soares Lima. Departamento de Enfermagem da Universidade Federal do Ceará.

Address: Rua Alexandre Baraúna, 1115, Rodolfo Teófilo, CEP: 60430-160. Fortaleza, CE, Brasil.

” adminhacs@hotmail.com

Keywords

Depression; Stroke;

Acute Hospital. 
mainly cardiovascular diseases, diabetes, cancer and chronic respiratory diseases [2]. The main causes this mortality are related with complications from cardiovascular disease, cerebrovascular and cancer. In this context, the stroke is a most predominant morbidity condition between cerebrovascular disease. There is a worldwide recognition that, in 2030, four million individuals may develop this disease. In the US, 795.000 people experience a new or recurrent episode, and one in four cases considered recurring events [3].

Patients with this diagnosis may have consequences that make it difficult to perform daily activities, affecting physical, psychological and social aspects. Depression is an important variable related to the worsening of quality of life in post-stroke patients, which limits the adherence to treatment, compromising the health perception, reducing the energy, social interaction and motivation [4].

Depression is considered, in this thought, a new chronic health condition that deserves special attention. Therefore, despite the stroke be an installed condition, we seek to know the risk factors for a new complication that may worsen the quality of life. Increased attention should be directed to individuals affected by stroke, with respect to depressive symptoms, since recognizing them, may be effective interventions directed drawn to supported self-care.

Depressive symptoms during post-stroke hospitalization are predictive for the occurrence of major depression six months after discharge. The evaluation of depressive symptoms helps for the identification of patients with stroke and risk of depression, facilitating the prevention and treatment [5].

This study aimed to identify the prevalence of depression in patients after stroke and the association between the clinical characteristics of patients with stroke and the presence of depression.

\section{Method}

Cross-sectional study, carried out from February to April 2013 in semi-intensive care unit specializing in the care of patients with acute stroke, located in a large hospital in Fortaleza, Ceará, Brazil.

The sampling process occurred at random, respecting the data collection period, which was held in two rounds, once a week, as release of the admission unit, resulting in a sample of 51 subjects. The participants met the following inclusion criteria: being admitted in the unit with a confirmed medical diagnosis of stroke and present focal neurological deficit on admission. The patients who presented complications and emergencies while collecting data were excluded.

Data were collected through one interview conducted using an instrument with the identification data; risk factors non-modifiable (age and sex) and modifiable (smoking, alcohol consumption and physical inactivity); and biological factors, such as hypertension and diabetes mellitus. Hamilton Depression Rating Scale (HDRS) was applied to investigate the psychological factor depression, which evaluates the intensity of depressive symptoms and the major depression detection, with 21 items scored 0-4, developed and validated for the assessment and quantification of depressive symptoms [6]. To establish the cases of depression the following criteria were considered: score equal to or less than 6 in HDRS = no depressive disorder or clinical remission; score between 7 and $17=$ mild depression; score between 18 and 24 = moderate depression; score greater than $25=$ severe depression [7].

Data were organized and analyzed in Microsoft Office Excel 2007 spreadsheet and subsequently transported to SPSS (version 20.0). For the determination of central tendency measure, the mean and standard deviation were calculated and the odds ratio was applied. The results were presented in table.

The ethical aspects established in Resolution No. $466 / 12$ by the National Health Council were res- 
pected. The research project was approved by the Ethics Committee on Research with human beings of the Federal University of Ceará, as the Protocol no. 010/11.

\section{Results}

Among the 51 patients in the sample, 29 (56.8\%) were male; 31 (60.7\%) were married or in stable relationships. The highest percentage of participants had less than 9 years of education (40-78.4\%), focusing on incomplete primary education (21$42.8 \%)$, followed by complete primary education $(14-28.5 \%)$.

The age of participants ranged from 16 to 78 years, with an average of 51 years $\pm 15.3 ; 75.5 \%$ had some occupation. We considered unemployed those who did not develop any gainful activity, as well as retired people, pensioners, students and housewives.

As for comorbidities before the stroke, the most prevalent was the Hypertension (36-70.59\%), followed by diabetes mellitus (DM) (9 to 17.65\%) and heart disease $(6-11,76 \%)$. The other investigated diseases showed lower percentage, such as nephropathy (1-1.96\%), cancer (CA) (1-1.96\%) and Acute Myocardial Infarction (AMI) (2-3,96\%). About risk factors (RF) modifiable, $80.4 \%$ were sedentary, $45.1 \%$ were smokers and $27.5 \%$ of alcoholics.

To investigate the presence of neurological deficits, it was found that 29 (56.9\%) subjects had slurred speech, although these changes have not prevented from communicating or answer questions, even with limitations. The motor deficit with impaired walking was present in 34 (66.7\%) patients who had lost the ability to walk even with assistance, due to hemiplegia or hemiparesis.

Regarding the presence of depression, 31 (61.7\%) patients had some depressive symptoms, 27 (52.9\%) of these classified as mild depression and 4 (7.8\%) with moderate depression. By associating the presence of depression with sociodemographic data, risk factors, comorbidities and neurological deficits, the mild and moderate categories were united into a single category, that is, depression (Table 1).

Table 1. Distribution of data based on association of depression with sociodemographic variables, modifiable and non-modifiable risk factors and clinical characteristics in patients with stroke. Fortaleza, 2013.

\begin{tabular}{|c|c|c|c|c|c|c|}
\hline \multirow{3}{*}{ Variable } & \multicolumn{4}{|c|}{ Depression } & \multirow{3}{*}{ RC- IC 95\% } & \multirow{3}{*}{$\mathbf{p}$} \\
\hline & \multicolumn{2}{|c|}{ Yes } & \multicolumn{2}{|c|}{ No } & & \\
\hline & $n$ & $\%$ & $n$ & $\%$ & & \\
\hline \multicolumn{7}{|c|}{ Socio-Demographic Data } \\
\hline \multicolumn{7}{|c|}{ Marital Status } \\
\hline With companion & 21 & 67.7 & 10 & 32.3 & $2.1(0.6-6.6)$ & \multirow{2}{*}{0.20} \\
\hline No companion & 10 & 50 & 10 & 50 & 1 & \\
\hline \multicolumn{7}{|l|}{ Education (years) } \\
\hline More than 9 & 6 & 66.7 & 3 & 33.3 & $1.4(0.3-6.7)$ & \multirow{2}{*}{0.61} \\
\hline Up to 9 & 23 & 57.5 & 17 & 42.5 & 1 & \\
\hline \multicolumn{7}{|l|}{ Occupation } \\
\hline No work & 10 & 76.9 & 3 & 23.1 & $2.6(0.6-11.4)$ & \multirow{2}{*}{0.16} \\
\hline Working & 21 & 55.3 & 17 & 44.7 & 1 & \\
\hline \multicolumn{7}{|c|}{ Modifiable Risk Factors } \\
\hline \multicolumn{7}{|l|}{ Physical activity } \\
\hline Yes & 3 & 30 & 7 & 70 & 1 & \multirow{2}{*}{0.26} \\
\hline No & 28 & 68.3 & 13 & 31.7 & $5(1.1-22)$ & \\
\hline \multicolumn{7}{|l|}{ Smoking } \\
\hline Yes & 14 & 60.9 & 9 & 39.1 & $1(0.3-3.1)$ & \multirow{2}{*}{0.99} \\
\hline No & 17 & 60.7 & 11 & 39.3 & 1 & \\
\hline \multicolumn{7}{|l|}{ Alcoholism } \\
\hline Yes & 9 & 64.3 & 5 & 35.7 & $1.2(0.3-4.3)$ & \multirow{2}{*}{0.75} \\
\hline No & 22 & 59.5 & 15 & 40.5 & 1 & \\
\hline \multicolumn{7}{|c|}{ Clinical characteristics } \\
\hline \multicolumn{7}{|c|}{ Neurological deficits } \\
\hline \multicolumn{7}{|l|}{ Speech disorders } \\
\hline Present & 20 & 69 & 9 & 31 & $2.2(0.7-7)$ & \multirow{2}{*}{0.16} \\
\hline Absent & 11 & 50 & 11 & 50 & 1 & \\
\hline \multicolumn{7}{|l|}{ Inability to walk } \\
\hline Present & 19 & 55.9 & 15 & 44.1 & 1 & \multirow{2}{*}{0.31} \\
\hline Absent & 12 & 70.6 & 5 & 29.4 & $1.8(0.5-6.5)$ & \\
\hline
\end{tabular}




\begin{tabular}{|c|c|c|c|c|c|c|}
\hline \multirow{3}{*}{ Variable } & \multicolumn{4}{|c|}{ Depression } & \multirow{3}{*}{ RC- IC 95\% } & \multirow{3}{*}{$\mathbf{p}$} \\
\hline & \multicolumn{2}{|c|}{ Yes } & \multicolumn{2}{|c|}{ No } & & \\
\hline & $\mathrm{n}$ & $\%$ & $n$ & $\%$ & & \\
\hline \multicolumn{7}{|c|}{ Clinical characteristics } \\
\hline \multicolumn{7}{|c|}{ Comorbidities } \\
\hline \multicolumn{7}{|l|}{ Diabetes } \\
\hline Yes & 5 & 55.6 & 4 & 44.4 & 1 & \multirow{2}{*}{0.72} \\
\hline No & 26 & 61.9 & 16 & 38.1 & $1.3(0.3-5.5)$ & \\
\hline \multicolumn{7}{|l|}{ Hypertension } \\
\hline Yes & 22 & 61.1 & 14 & 38.9 & $1(0.3-3.5)$ & \multirow{2}{*}{0.94} \\
\hline No & 9 & 60 & 6 & 40 & 1 & \\
\hline \multicolumn{7}{|l|}{ Hypertension } \\
\hline Yes & 4 & 66.7 & 2 & 33.3 & $1.3(0.2-8)$ & \multirow{2}{*}{0.75} \\
\hline No & 27 & 60 & 18 & 40 & 1 & \\
\hline
\end{tabular}

People who have partners were 2.1 more likely to stroke, compared to those without a partner.

Subjects with higher education had 40\% more likely to have depressive symptoms. It is believed that the fact that individuals are better educated, makes them aware of the disease and the complications it can cause, making them better able to recognize and refer the symptoms. Those who had no occupation, i.e., a steady job, had 2.6 times more likely to have symptoms of depression, reaching 1.4 times.

For non-modifiable risk factors, it is perceived that women are $20 \%$ more likely to develop depression when compared to men. Although most participants were aged over 40, it was found that the younger the better the chance ( 2.3 times) to develop this injury.

With regard to modifiable risk factors, physical inactivity was the most significant factor for depression, as have it before the stroke increased by 5 times the chance of developing mild or moderate depressive symptoms after this event. This chance can reach up to 22 times more compared to physically active people. Although to a lesser extent, alcohol consumption showed interfere with the onset of depression, with $20 \%$ higher chance. For smokers, there is an equal chance of a non-smoker develop depression.
As for neurological deficits, it was identified that the subjects with speech disorders have 2.2 times more likely to acquire mild to moderate depressive symptoms. On the other hand, the inability to walk did not affect the acquisition of these symptoms, whereas the individual with the absence of this deficit is $80 \%$ more likely to develop depression.

With respect to comorbidities, it was demonstrated that non-diabetic and heart disease patients have a $30 \%$ chance to further develop depression. There is no increase of chances for hypertensive; it is also likely that a non hypertensive individual will have depression.

\section{Discussion}

Patients who have companion have more chance of having depressive disorder than those without partners. This fact has been proven in other population surveys showed more frequency in this diagnosis among married or in a stable relationship [8]. Similar data were found as a condition of marriage, in which $54.9 \%$ had a partner.

As for education, the data from this study were different from a similar study in which the study time was, on average, 2.58 years ( $S D \pm 3.4)$, showing the low level of education of the population [9].

Concerning the occupation, in this study the subjects without occupation were more likely to develop depression, a fact that was congruent in a study carried with three patients with post-stroke depression (PSD). They could not return to previous occupation to the stroke, which is a factor that favours the psychological diseases depression-like. Although the PSD presents high prevalence it remains poorly diagnosed [10].

The incidence of stroke between genders is diverse, in which, depending on the context, can be prevalent in men or women $[9,11]$. A similar study involving patients with this diagnosis showed consistent results where $54.9 \%$ were women [9]. 
The presence of depression was observed in $61.7 \%$ of patients investigated, affecting more women and young people. When investigating patients post-stroke, Brazilian researchers revealed most alarming and divergent results, by showing that $90.5 \%$ of patients had some degree of depression, 50\% classified as moderate or severe degree. These indices were higher in females and there was no difference between age, where the rates of depression scores were fair in all age groups [12]. Researchers in Thailand, however, showed that men are more likely to develop psychological disorders after a stroke, but age was not a predisposing factor [13]. The experience of these symptoms, as well as the severity among women may be constant at all stages of life [14].

Although other studies have not highlighted age as a risk, the presented survey showed that young people are more susceptible to the disease. This evidence may be related to the fact that in this period of life, the majority is in the production phase, associated with neurological deficits that bring limitations to the individual. Analyzing these two results, it is assumed that young women who do not have an occupation are more susceptible to the disease.

Modifiable risk factors are associated with the development of various cardiovascular diseases and mental disorders. It is known that daily physical activity is closely related with the lowest risk of incident depressive symptoms [15]. This was reinforced in the research in question when it identified that physical inactivity increases by 5 times the chance of developing these conditions.

Alcoholism, in turn, is a condition present among the depressive ones [8]. Although the study presented here shows that the chance of a smoker have these symptoms is the same for non-smokers (OR $=1$ ). Smoking is considered one of major determinants of the risk of depression. Smokers, besides having a greater likelihood to develop this disorder, they present a decreased chance of recovery [16].
Regarding clinical characteristics, changes in speech, particularly aphasia, is considered a predictive factor for the development of depression after stroke [17], and according to the results presented in the presence of neurological deficit increases in 2 times the chance. Opposed to this study, the literature indicates that individuals who do not roam freely after this event have some degree of depression [12]. Another literature shows that the prevalence of motor deficit after stroke in individuals with depression is similar among those who do not develop this disorder, while the deficit in speech is more frequent among those with this diagnosis [8].

The presence of some comorbidities plays an important role, and therefore an investigation of these conditions is necessary, in order to avoid a worsening of symptoms of a stroke.

Some authors, investigaing cardiovascular risk factors in patients with this involvement, revealed that hypertension, physical inactivity, diabetes and smoking are seen as the main risk factors, accounting for $68.8 \%, 65.6 \%, 20,3 \%$ and $9.4 \%$, respectively [18]. Some of these data corroborate the present study, by highlighting hypertension (70.59\%) and physical inactivity (80.4\%) as the most prevalent.

Regarding the presence of comorbidities there are differences in the scientific community. A multicenter study carried out in three hospitals in the Netherlands, with patients who had characteristics similar to our study has shown that the presence of heart disease and hypertension was more prevalent in non depressive ones and that DM was more prevalent among depressive [8]. When analyzing the association between vascular risk factors and poststroke depression among Canadians, it was shown that only hypertension was an independent predictor factor for the presence of depressive symptoms [19].

In this study, the result in relation to DM and depression was the reverse of the expected. It is important to have a pathophysiological approach 
to ascertain the mechanisms that explain the association between depression and clinical conditions. Even for diabetes, concomitant with the psychological impact of the loss of glycemic control, a promising line of research is the investigation of an impairment of the central nervous system by diabetes as a possible mechanism to explain the association with depression [20].

\section{Conclusion}

Based on these, it is clear that the presence of comorbidities in people with depression after stroke vary according to the circumstances of each population.

This study showed that among patients who have suffered a stroke, young women, with companions and unemployed are more likely to develop depression. It was also possible to notice an alarming link between physical inactivity and depression. We see, on this, the need to expand research in this context with longitudinal studies so these and other factors can be controlled through time.

An important limitation of this study is the number of individuals investigated, suggesting, therefore, that further studies should be conducted with this goal by addressing a larger number of participants. Studying on depression after a thrombotic event, such as stroke, brings a contribution to the scientific community and the professionals who work with this profile of patients.

It is suggested that the presence of symptoms that characterize depression are identified as early as possible after the event in order to implement health education strategies and reorienting health services to promote the health of this group. By knowing this reality subsequent complications can be avoided that may aggravate the initial context installed and the emergence of this new chronic health condition.

The necessity to know other factors that were not included in this study as the professional / patient relationship, family support and social support networks in the community where the patient returns after diagnosis of stroke is relevant. It is believed that this study has contributed to the advance of research in this area, but there is awareness that much still needs to be done to actually contribute to the mental health of this population.

\section{References}

1. World Health Organization (2014). Noncommunicable diseases country profiles. Available in: http://apps.who.int/iris/ bitstream/10665/128038/1/9789241507509 eng.pdf access on 22 jan. 2016.

2. Campolina AG, Adami F, Santos JLF., Lebrão ML. A transição de saúde e as mudanças na expectativa de vida saudável da população idosa: possíveis impactos da prevenção de doenças crônicas. Cad. Saúde Pública. 2013; 29(6): 1217-29.

3. Roger VL, Go AS, Lloyd-Jones DM, Benjamin EJ, Berry JD, Borden WB; et al. Heart disease and stroke statistics-2012 update: a report from the American Heart Association. Circulation. 2012; 125(1): 2-220.

4. Terroni LMN, Mattos PF, Sobreiro MFM, Guajardo VD. Depressão pós-AVC: aspectos psicológicos, neuropsicológicos, eixo HHA, correlato neuroanatômico e tratamento. Rev Psiq Clín. 2009; 36(3): 100-8

5. Lewin-Richter A, Volz M, Jöbges M, Werheid K. Predictivity of Early Depressive Symptoms for Post-Stroke Depression. J Nutr Health Aging. 2015; 19(7): 754-8.

6. Machado AS, Machado DT, Portela PG, Fontenelle-Neto C, Cruz ÁA. Frequência de depressão em pacientes ambulatoriais com asma moderada e grave. Rev Bras Alerg Imunopatol. 2001; 24(4): 90-7

7. Dal Bó MJ, Silva GS, Machado DFGP, Silva RM. Prevalence of depressive symptoms in patients admitted to clinical sector in a general hospital in the South of Santa Catarina. Rev Bras Clin Med. 2011; 9(4): 264-8.

8. Man-van Ginkel JM, Hafsteinsdóttir TB, Lindeman E, Ettema RGA, Grobbee DE, Schuurmans MJ. In-Hospital Risk Prediction for Post-stroke Depression: Development and Validation of the Post-stroke Depression Prediction Scale. Stroke. 2013; 44: 4412445. 
9. Cavalcante TF, Araújo TL, Moreira RP, Santiago JM. Perfil socioeconômico de pacientes internados com acidente vascular encefálico Rev. RENE. 2010; 11(4): 154-62.

10. Oliveira AIC, Silveira KRM Utilização da CIF em pacientes com sequelas de AVC. Rev Neurocienc. 2011; 19(4): 653-62.

11. Silva MACO. AVE e o gênero-perfil do doente com AVE e eventuais semelhanças entre os sexos [dissertation]. Beira Interior University. 2012.

12. Soares NM, Galdino GS, Araújo DP. Index of Depression in Subjects Post-Stroke in the County of Campina Grande - PB. Rev Neurocienc. 2014; 22(2): 215-20.

13. Kuptniratsaikul1 V, Kovindha A, Suethanapornkul S, Manimmanakorn N, Archongka Y. Long-term morbidities in stroke survivors: a prospective multicenter study of Thai stroke rehabilitation registry. BMC Geriatrics. 2013; 13: 33.

14. Sanner JE, Frazier L, Udtha M. Self-reported depressive symptoms in women hospitalized for acute coronary syndrome. Journal of Psychiatric and Mental Health Nursing. 2013; 20: 913-20.

15. Smith TL, Masaki KH, Fong K, Abbott RD, Ross GW, Petrovitch $\mathrm{H}$, et al. Effect of walking distance on 8-year incident depressive symptoms in elderly men with and without chronic disease: the Honolulu-Asia Aging Study. J Am Geriatr Soc. 2010; 58(8): 1447-52.

16. Khaled SM, Bulloch AG, Williams JV, Hill JC, Lavorato DH, Patten $\mathrm{SB}$. Persistent heavy smoking as risk factor for major depression (MD) incidence-evidence from a longitudinal Canadian cohort of the National Population Health Survey. J Psychiatr Res. 2012; 46(4): 436-43.

17. Barbosa AC, Medeiros LS, Duarte N, Meneses C. Factores preditivos de depressão pós-acidente vascular cerebral. Acta Med Port. 2011; 24(S2), 175-80.

18. Rodrigues ESR, Castro KA, Barbosa AA, Herrera DSC, Pereira AM, Takada JAP. Fatores de risco cardiovascular em pacientes com acidente vascular cerebral. Rev. Amaz. 2013; 2(1): 21-28.

19. Tennen G., Herrmann N., Black S.E., Levy K.S., Cappell J., Li A., Lanctôt K.L. Are Vascular Risk Factors Associated With PostStroke Depressive Symptoms? J Geriatr Psychiatry Neurol. 2011; 24(4): 215-21.

20. Fraguas R. Depressão e condições médicas. Rev. psiquiatr. clín. 2009; 36(supl.3). Available from <http://www.scielo.br/scielo. php?script=sci arttext\&pid=S0101-60832009000900001\&lng =en\&nrm=iso> . access on 17 Nov. 2015.
Publish in International Archives of Medicine

International Archives of Medicine is an open access journal publishing articles encompassing all aspects of medical science and clinical practice. IAM is considered a megajournal with independent sections on all areas of medicine. IAM is a really international journal with authors and board members from all around the world. The journal is widely indexed and classified Q1 in category Medicine. 